\title{
Long-Term Symptoms Onset and Heterotopic Bone Formation around a Total Temporomandibular Joint Prosthesis: a Case Report
}

\author{
Luca Guarda-Nardini $^{1}$, Daniele Manfredini ${ }^{1}$, Marco Olivo ${ }^{1}$, Giuseppe Ferronato ${ }^{1}$ \\ ${ }^{1}$ Department of Maxillofacial Surgery, University of Padova, Italy.
}

\author{
Corresponding Author: \\ Marco Olivo \\ Via Galvani n 2, 34070 Turriaco (GO) \\ Italy \\ E-mail: molivo@hotmail.it
}

\begin{abstract}
Background: The literature on total alloplastic temporomandibular joint (TMJ) reconstructions is encouraging, and studies on total alloplastic TMJ replacements outcomes showed acceptable improvements in terms of both pain levels and jaw function. Nevertheless, some adverse events, such as heterotopic bone formation around the implanted prosthesis, may occur. In consideration of that, the present manuscript describes a case of heterotopic bone formation around a total temporomandibular joint prosthesis, which occurred several years after the implant.

Methods: The present manuscript describes a case of heterotopic bone formation around a total TMJ prosthesis, which occurred several years after the implant in patients, who previously underwent multiple failed TMJ surgeries.

Results: Ten years after the surgical TMJ replacement to solve an ankylotic bone block, the patient came to our attention again referring a progressive limitation in mouth opening. A computerized tomography showed evidence of marked heterotopic bone formation in the medial aspects of the joint, where a new-born ankylotic block occupied most part of the gap created by resecting the coronoid process at the time of the TMJ prosthesis insertion.

Conclusions: Despite this adverse event has been sometimes described in the literature, this is the first case in which its occurrence happened several years after the temporomandibular joint replacement. It can be suggested that an accurate assessment of pre-operative risk factors for re-ankylosis (e.g., patients with multiple failed temporomandibular joint surgeries) and within-intervention prevention (e.g., strategies to keep the bone interfaces around the implant separated) should be better standardized and define in future studies.
\end{abstract}

Keywords: ankylosis; heterotopic ossification; temporomandibular joint; temporomandibular joint disc; temporomandibular joint disorders.

Accepted for publication: 28 March 2014

To cite this article:

Guarda-Nardini L, Manfredini D, Olivo M, Ferronato G. Long-Term Symptoms Onset and Heterotopic Bone Formation around a Total Temporomandibular Joint Prosthesis: a Case Report.

URL: http://www.ejomr.org/JOMR/archives/2014/1/e6/v5n1e6ht.pdf

doi: $10.5037 /$ jomr.2014.5106 


\section{INTRODUCTION}

Despite the catastrophic early experiences on alloplastic materials and prosthetic systems for temporomandibular joint (TMJ) rehabilitation (i.e. Proplast-Teflon/Silastic) [1-3], in the recent years, new temporomandibular joint prosthetic systems have been introduced as a treatment option in the management of patients who had previously undergone multiple failed TMJ non-surgical and surgical therapies $[\underline{4}, \underline{5}]$.

In the new millennium, several studies on the outcomes of new-generation total alloplastic TMJ replacement showed acceptable improvements in terms of both pain levels and jaw function, thus making these interventions worthy of further evaluation [6-8]. The most recent systematic review on the argument reported promising treatment outcomes, with good improvements for both subjective (pain levels) and objective (jaw function) clinical parameters. Nonetheless, a generalization of results was limited by the low number of available studies, which involved only few surgeons and manufacturers, as well as by the reduced overall number of treated patients, which requires an enlargement to have a deeper appraise of the potential complications associated with these surgeries [9].

Since the publication of that last review, some others papers have been published with longer follow-up periods, in support of the favourable outcomes of total TMJ replacement $[\underline{10}, \underline{11}]$. Also, some interesting reports described the potential adverse events, which seem to occur in a very low percentage of patients [12-14].

In consideration of that, the present manuscript describes a case of heterotopic bone formation around a total temporomandibular joint prosthesis, which occurred several years after the implant.

\section{CASE DESCRIPTION AND RESULTS}

In 2003, a 35 year-old female patient was referred to the Department of Maxillofacial Surgery, University of Padua, Italy, for the treatment of a severe mouth opening restriction and pain in the TMJ. The patient had no other comorbidity and was taking only pain medication (NSAIDs) when needed; she gave a history of pain in the TMJ area and had undergone two previous operations (i.e., a disc repositioning surgery at the age of 25 years, and a discectomy with condylar remodelling at the age of 32 years) at other maxillofacial surgery clinics. After the second surgery, the range of mandibular movements decreased rapidly, and the patient was referred to our clinic. The maximum mouth opening was $5 \mathrm{~mm}$, with absence of end-feel distance, and computerized tomography showed ankylosis of the left TMJ (Figure 1). A Research Diagnostic Criteria for TMD (RDC/TMD) [15] Axis I diagnosis of disc displacement with reduction (group II a) and osteoarthritis (group III b) was made for the right joint.

At that time, several surgical options were considered to relieve TMJ ankylosis and restore jaw function, ranging from the quite abandoned gap arthroplasty to interpositional arthroplasty, which provided the insertion of a biological (temporalis fascia, temporal muscle flap) or non-biological material (acrylic, silastic) between the bone structures [16-18]. Nevertheless, patients undergoing multiple previous operations were described as having a higher risk of re-ankylosis, and a TMJ replacement should be considered [4]. The literature also suggested that a total TMJ replacement system is preferable to a partial replacement to avoid excessive stress and wear of the articular bone surface working against the prosthesis, which can prevent long-term functional restoration $[19,20]$.

Considering these concerns, a total TMJ prosthesis in the left joint was preferred to the other surgical options, and the patient was scheduled for surgery.

The total TMJ replacement system is a "ball and socket" type prosthetic joint similar to a hip implant. The total TMJ replacement system comprises three components [9]:

The condylar (or mandibular) implant, made of metal Cobalt-Chromium-Molybdenum (Co-Cr-Mo) alloy or Titanium alloy. In both cases the implants have a roughened titanium porous coating on the implant surface that contacts bone. Co-Cr-Mo alloy contains nickel.

The fossa implant, made of a hard, plastic

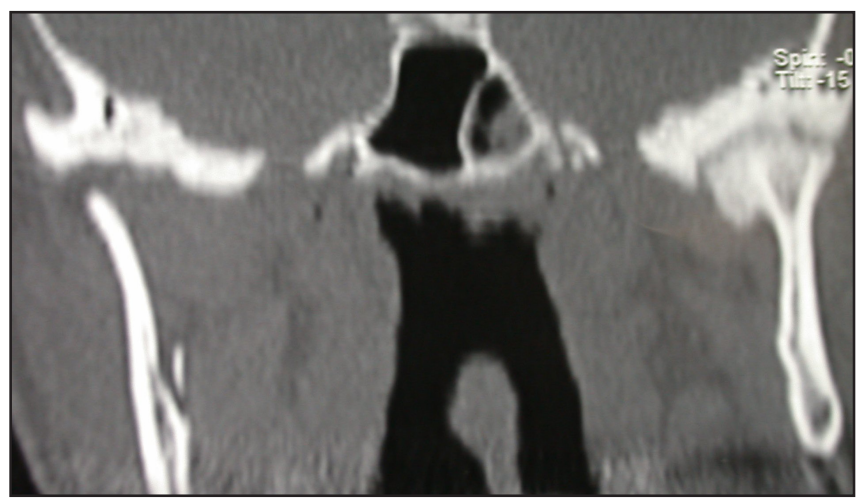

Figure 1. Computerized tomography showing ankylosis of the left tempormandibular joint. 
polyethylene. The fossa is made of high density polyethylene that has shown excellent wear resistance during mechanical testing.

The screws, made of titanium alloy are used to attach both the condylar and the fossa implants to bone.

In this case a total TMJ stock prosthesis was inserted (Biomet/Lorenz, Warsaw, IN, USA) [20]. It was provided in three different sizes for both the condylar/mandibular and the fossa implants. The fossa component is made up of ultra-high molecular weight polyethylene (UHMWPE), while the condylar/ mandibular component is made up of a Co-Cr-Mo alloy with titanium surfaces. The former is fixed to bone tissue by means of $4-7$ screws of $2.0 \mathrm{~mm}$ diameter, while the latter is fixed by means of $7-11$ screws of $2.7 \mathrm{~mm}$ diameter.

Two surgical phases characterized the intervention, viz., the removal of the ankylotic block and the positioning of the TMJ prosthesis. Thus, both preauricular access to the TMJ and temporal bone and a posteroinferior submandibular incision for access to the mandibular ramus were required. The superior incision has a $45^{\circ}$ release into the temporal hairline, and the dissection is kept as posterior as possible to avoid the facial nerve. The inferior incision was almost vertical, viz., perpendicular to the lower two-thirds of the posterior border of the ramus). Once access to the TMJ was gained through the preauricular incision, the release of the ankylosis was performed (Figure 2). A $5-10 \mathrm{~mm}$ gap between the recountoured glenoid fossa and the mandible was created by removing the fibrous scar and heterotopic osseus tissue with surgical burs and chisels. Remodeling of the glenoid fossa and a full excision of the coronoid process were performed to fit and fix the fossa component of the prosthesis and to reduce the risk for re-ankylosis. The patient was then placed in the post-operatory intermaxillary relationship,

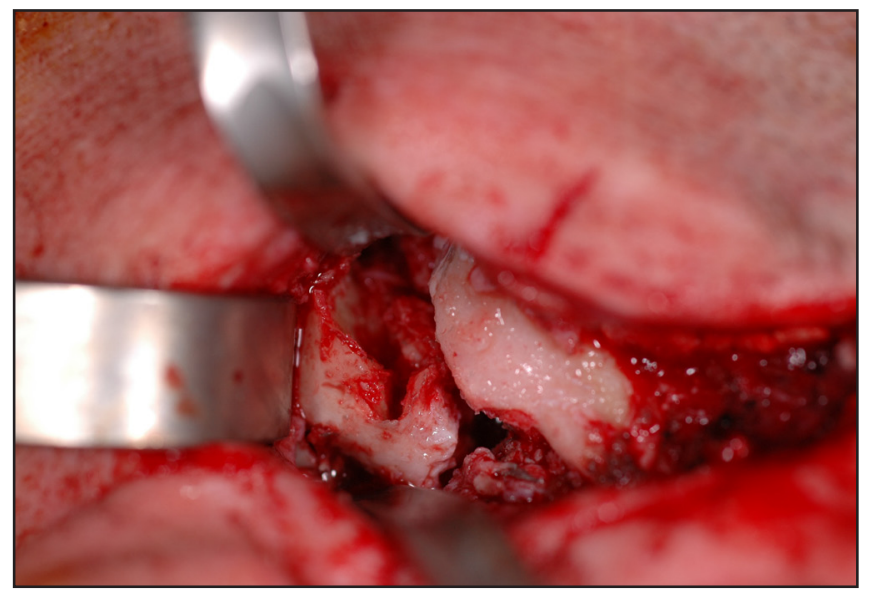

Figure 2. Intraoperative photograph showing aggressive excision of the fibrous and/or bony mass. which was secured with temporary wire fixation; condylectomy was then performed and the mandibular component of the prosthesis was placed and fixed.

The intermaxillary fixation was then removed and the patient's mandible was manipulated to ensure that no obstructions to joint movement or improper fitting between the two prosthetic components were present. The patient was also forced intra-operatively to maximum mouth opening, in order to break adhesions on the contralateral side. Only after verifying the correct functioning and freedom of movement of the implant, the patient was then sutured and a control ortopantomography was taken (Figure 3).

In this case, the postoperative course was uneventful, and only pain medication (NSAIDs as needed) and antibiotics (amoxicillin/clavulanate cp $1 \mathrm{~g}$ every 12 hours for 7 days) were prescribed. There was no motor deficit on either side of the face. Functional rehabilitation was started one week after surgery, by a combination of active and passive exercises. In particular, the patient was given an intensive regime of passive motion (TheraBite Jaw Motion Rehabilitation System $^{\circledR}$, Therabite, Philadelphia, PA, USA), which are fundamental to improve jaw mobility after surgical procedures on the TMJ. The patient was asked to perform passive exercises for the first three months after surgery, and vigorous active physiotherapy was then introduced to maintain the mobility. A cycle of five injections (one per week) of $1 \mathrm{ml}$ low-molecular weight hyaluronic acid (Sinovial $^{\circledR}$, IBSA Farmaceutici Italia, Lodi, Italy) injections was also provided to the contralateral TMJ according to the technique in use at that moment [21]. The patient was followed up monthly during the first year, and mouth opening at twelve months was up to $41 \mathrm{~mm}$, with no pain recurrence. The patient then failed to attend the clinic in the following years due to the distance between her hometown and the clinic,

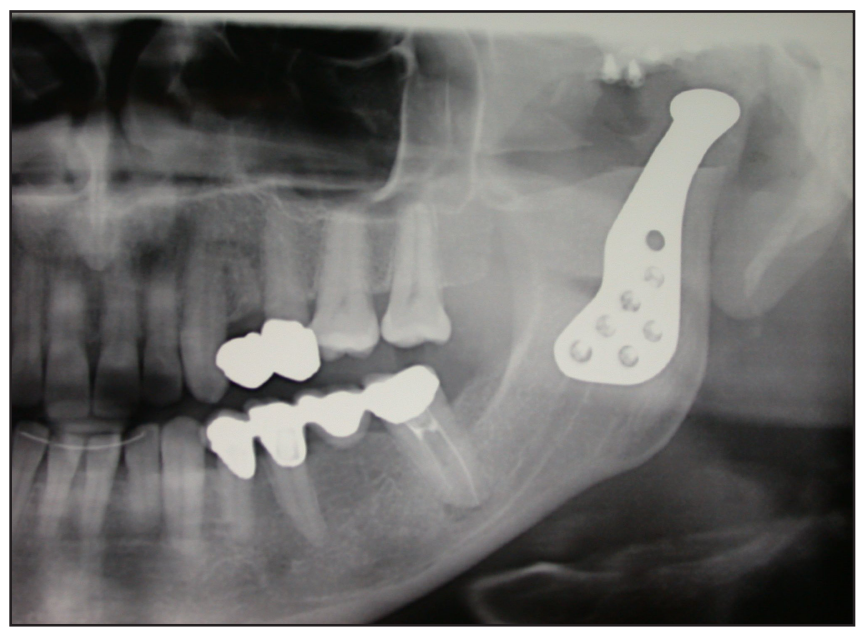

Figure 3. Ortopantomography performed immediately after surgery. 
and during a phone contact two years after the last follow-up assessment she declared everything was fine, and that she was able to open the mouth straight without feeling pain.

Ten years after the surgical TMJ replacement, the patient came to our attention again referring a progressive limitation in mouth opening. A computerized tomography showed evidence of marked heterotopic bone formation in the medial aspects of the joint (Figures 4 and 5). The new ankylotic block occupied most part of the gap created by resecting the coronoid process at the time of the TMJ prosthesis insertion, and it was responsible for the reduced jaw mobility. Based on this adverse event, the patient was scheduled for re-intervention and some surgical options to try preventing re-ankylosis are currently under consideration.

\section{DISCUSSION}

Data on total TMJ replacements suggest that a history of multiple previous failed operations is the most common indication for joint replacement, and patients with severe osteoarthritis, inflammatory arthrosis, connective or autoimmune disease, ankylosis, absent or deformed structures, congenital deformities, and chronic pain also underwent the total joint replacement $[\underline{19}, \underline{22}]$. Literature data suggested that total alloplastic TMJ replacements interventions offer good outcomes, and reported improvements are good for both subjective (pain levels) and objective

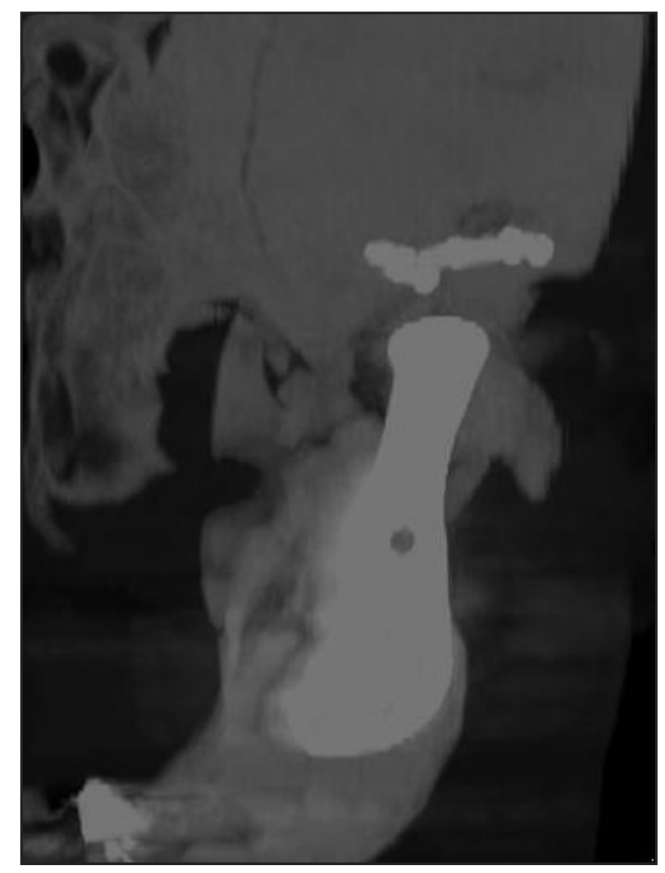

Figure 4. Computerized tomography showing heterotopic bone formation around the TMJ prosthesis. (jaw function) clinical parameters, even though a generalization of results is limited by the low number of available studies, which involved few surgeons and manufacturers [?].

Despite the increasing evidence in support of longterm positive outcomes of TMJ total replacement prostheses, the occurrence of some unfavourable events cannot be disregarded [11]. Among these, heterotopic bone formation around the implanted prosthesis is a rare condition that was first described up to two decades ago [2]3]. Since then, only a few case series were reported, describing the potential usefulness of re-intervention strategies, with not so clear data in terms of the postoperative spans before re-ankylosis $[12,13]$. In the case under description, the peculiarity with respect to previous literature reports was the long time span occurring between the insertion of the prosthesis and the patient's complain of limited mouth opening due to joint fibrosis and new-bone formation. The patient was inserted a total TMJ replacement ten years before she recalled our clinic because of mouth opening restriction. At the time of the prosthetic implant, a full-thickness dissection of the coronoid process was performed as an ancillary strategy to prevent re-ankylosis, and the patient was followed-up several times during the first year, showing no signs of any adverse events. Based on this observation, it seems plausible to suggest that longer observation times are required before the occurrence of heterotopic bone formation after TMJ prosthesis insertions can be ruled out. Also, some strategies that appear promising to reduce the complication rates, such as the placement of autologous fat grafts around the prosthesis, need to be taken into account for their effective usefulness by designing clinical trials that also take into account for the potential risk (i.e., increased risk for postsurgical infection) to-benefit (i.e., reduced risk of

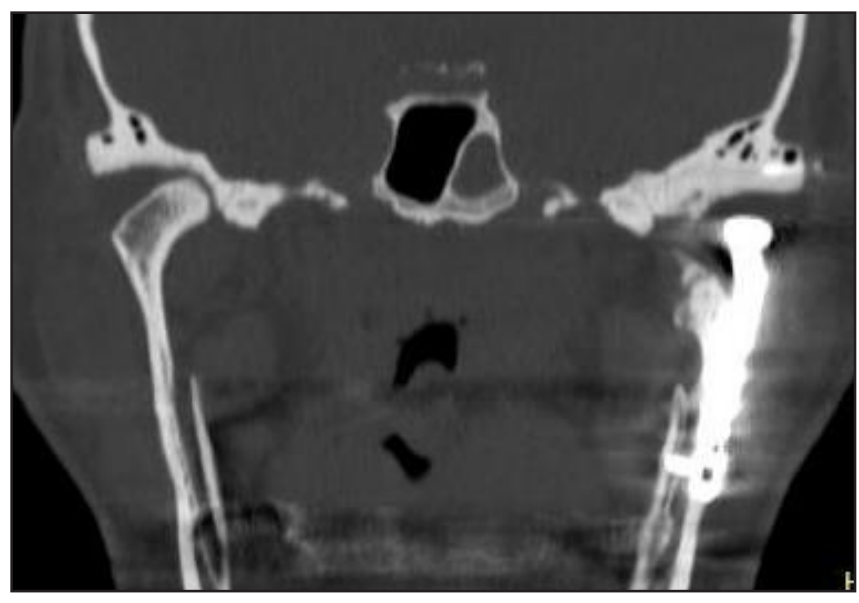

Figure 5. Computerized tomography showing the new bone in the medial aspects of the joint. 
heterotopic bone formation) ratio. On the other hand, studies at the tissue level are needed to assess the possible predisposition to heterotopic bone formation on an individual basis, given the increasing number of reports on patients who undergo multiple failed TMJ surgeries.

\section{CONCLUSIONS}

The present report describes a case of heterotopic bone formation around a total temporomandibular joint alloplastic prosthesis. Despite this adverse event has been sometimes described in the literature, in this particular case its occurrence happened several years after the temporomandibular joint replacement. Based on this observation, even if keeping in mind the low scientific relevance of this single report, it can be suggested that an accurate assessment of pre-operative risk factors for re-ankylosis (e.g., patients with multiple failed temporomandibular joint surgeries) and a within-intervention prevention (e.g., strategies to keep the bone interfaces around the implant separated) should be better standardized and define in future studies.

\section{ACKNOWLEDGMENTS AND DISCLOSURE STATEMENTS}

The author declares that this research was conducted without any commercial or financial relationships that could be construed as a potential conflict of interest.

\section{REFERENCES}

1. Feinerman DM, Piecuch JF. Long-term retrospective analysis of twenty-three Proplast-Teflon temporomandibular joint interpositional implants. Int J Oral Maxillofac Surg. 1993 Feb;22(1):11-6. [Medline: 8459115] [doi: 10.1016/S0901-5027(05)80348-0]

2. Henry $\mathrm{CH}$, Wolford LM. Treatment outcomes for temporomandibular joint reconstruction after Proplast-Teflon implant failure. J Oral Maxillofac Surg. 1993 Apr;51(4):352-8; discussion 359-60. [Medline: 8450350] [doi: 10.1016/S0278-2391(10)80343-X]

3. Kearns GJ, Perrott DH, Kaban LB. A protocol for the management of failed alloplastic temporomandibular joint disc implants. J Oral Maxillofac Surg. 1995 Nov;53(11):1240-7; discussion 1248-9. [Medline: 7562188] [doi: 10.1016/0278-2391(95)90577-4]

4. Mercuri LG. Alloplastic temporomandibular joint reconstruction. Oral Surg Oral Med Oral Pathol Oral Radiol Endod. 1998 Jun;85(6):631-7. Review. [Medline: 9638694] [doi: 10.1016/S1079-2104(98)90028-2]

5. Driemel O, Braun S, Müller-Richter UD, Behr M, Reichert TE, Kunkel M, Reich R. Historical development of alloplastic temporomandibular joint replacement after 1945 and state of the art. Int J Oral Maxillofac Surg. 2009 Sep;38(9):909-20. Epub 2009 May 21. Review. [Medline: 19464145] [doi: 10.1016/j.ijom.2009.01.022]

6. Mercuri LG, Wolford LM, Sanders B, White RD, Giobbie-Hurder A. Long-term follow-up of the CAD/CAM patient fitted total temporomandibular joint reconstruction system. J Oral Maxillofac Surg. 2002 Dec;60(12):1440-8. [Medline: 12465008] [doi: 10.1053/joms.2002.36103]

7. Speculand B, Hensher R, Powell D. Total prosthetic replacement of the TMJ: experience with two systems 1988-1997. Br J Oral Maxillofac Surg. 2000 Aug;38(4):360-9. [Medline: 10922169] [doi: 10.1054/bjom.2000.0338]

8. Pinto LP, Wolford LM, Buschang PH, Bernardi FH, Gonçalves JR, Cassano DS. Maxillo-mandibular counterclockwise rotation and mandibular advancement with TMJ Concepts total joint prostheses: part III--pain and dysfunction outcomes. Int J Oral Maxillofac Surg. 2009 Apr;38(4):326-31. Epub 2009 Jan 6. [Medline: 19128943] [doi: 10.1016/j.ijom.2008.11.016]

9. Guarda-Nardini L, Manfredini D, Ferronato G. Temporomandibular joint total replacement prosthesis: current knowledge and considerations for the future. Int J Oral Maxillofac Surg. 2008 Feb;37(2):103-10. Epub 2007 Nov 19. Review. [Medline: 18022347 ] [doi: $10.1016 /$ j.ijom.2007.09.175]

10. Leandro LF, Ono HY, Loureiro CC, Marinho K, Guevara HA. A ten-year experience and followup of three hundred patients fitted with the Biomet/Lorenz Microfixation TMJ replacement system. Int J Oral Maxillofac Surg. 2013 Aug;42(8):1007-13. Epub 2013 Jun 12. [Medline: 23769150] [doi: 10.1016/j.ijom.2013.04.018]

11. Mercuri LG. Alloplastic temporomandibular joint replacement: rationale for the use of custom devices. Int J Oral Maxillofac Surg. 2012 Sep;41(9):1033-40. Epub 2012 Jul 4. Review. [Medline: 22771166] [doi: 10.1016/j.ijom.2012.05.032] 
12. Mercuri LG, Ali FA, Woolson R. Outcomes of total alloplastic replacement with periarticular autogenous fat grafting for management of reankylosis of the temporomandibular joint. J Oral Maxillofac Surg. 2008 Sep;66(9):1794-803. [Medline: 18718385] [doi: 10.1016/j.joms.2008.04.004]

13. Wolford LM, Morales-Ryan CA, Morales PG, Cassano DS. Autologous fat grafts placed around temporomandibular joint total joint prostheses to prevent heterotopic bone formation. Proc (Bayl Univ Med Cent). 2008 Jul;21(3):248-54. [Medline: 18628972] [PMC free article: 2446413]

14. Machon V, Hirjak D, Foltan R. Open bite as a complication of total temporomandibular joint replacement: a case report. Oral Surg Oral Med Oral Pathol Oral Radiol. 2012 Oct;114(4):e6-8. Epub 2012 Mar 3. [Medline: 22986256] [doi: 10.1016/j.000o.2011.09.011]

15. Dworkin SF, LeResche L. Research diagnostic criteria for temporomandibular disorders: review, criteria, examinations and specifications, critique. J Craniomandib Disord. 1992 Fall;6(4):301-55. Review. [Medline: 1298767]

16. Erol B, Tanrikulu R, Görgün B. A clinical study on ankylosis of the temporomandibular joint. J Craniomaxillofac Surg. 2006 Mar;34(2):100-6. Epub 2006 Jan 19 [Medline: 16423530] [doi: 10.1016/j.jcms.2005.07.008]

17. Manfredini D, Bucci MB, Guarda-Nardini L. Temporomandibular joint bilateral post-traumatic ankylosis: a report of a case treated with interpositional arthroplasty. Minerva Stomatol. 2009 Jan-Feb;58(1-2):35-42. English, Italian. [Medline: 19234435]

18. Manganello-Souza LC, Mariani PB. Temporomandibular joint ankylosis: report of 14 cases. Int J Oral Maxillofac Surg. 2003 Feb;32(1):24-9. [Medline: 12653228] [doi: 10.1054/ijom.2002.0308]

19. Mercuri LG. Considering total temporomandibular joint replacement. Cranio.1999 Jan;17(1):44-8. Review. [Medline: 10425929]

20. Quinn PD. Lorenz Prosthesis. Oral Maxillofac Surg Clin North Am 2000;12:93-104.

21. Guarda-Nardini L, Stifano M, Brombin C, Salmaso L, Manfredini D. A one-year case series of arthrocentesis with hyaluronic acid injections for temporomandibular joint osteoarthritis. Oral Surg Oral Med Oral Pathol Oral Radiol Endod. 2007 Jun;103(6):e14-22. Epub 2007 Apr 6. [Medline: 17419078] [doi: 10.1016/j.tripleo.2006.12.021]

22. Wolford LM, Pitta MC, Reiche-Fischel O, Franco PF. TMJ Concepts/Techmedica custom-made TMJ total joint prosthesis: 5-year follow-up study. Int J Oral Maxillofac Surg. 2003 Jun;32(3):268-74. [Medline: 12767873] [doi: 10.1054/ijom.2002.0350]

23. Lindqvist C, Söderholm AL, Hallikainen D, Sjövall L. Erosion and heterotopic bone formation after alloplastic temporomandibular joint reconstruction. J Oral Maxillofac Surg. 1992 Sep;50(9):942-9; discussion 950. [Medline: 1506969] [doi: 10.1016/0278-2391(92)90051-Z]

\section{To cite this article:}

Guarda-Nardini L, Manfredini D, Olivo M, Ferronato G. Long-Term Symptoms Onset and Heterotopic Bone Formation around a Total Temporomandibular Joint Prosthesis: a Case Report.

J Oral Maxillofac Res 2014;5(1):e6

URL: http://www.ejomr.org/JOMR/archives/2014/1/e6/v5n1e6ht.pdf

doi: $10.5037 /$ jomr.2014.5106

Copyright (C) Guarda-Nardini L, Manfredini D, Olivo M, Ferronato G. Published in the JOURNAL OF ORAL \& MAXILLOFACIAL RESEARCH (http://www.ejomr.org), 1 April 2014.

This is an open-access article, first published in the JOURNAL OF ORAL \& MAXILLOFACIAL RESEARCH, distributed under the terms of the Creative Commons Attribution-Noncommercial-No Derivative Works 3.0 Unported License, which permits unrestricted non-commercial use, distribution, and reproduction in any medium, provided the original work and is properly cited. The copyright, license information and link to the original publication on (http://www.ejomr.org) must be included. 